\title{
Behavior Disorders: knowledge and actions of health professionals and social work
}

\author{
Transtornos do Comportamento: conhecimentos e ações de profissionais de saúde e assistência social \\ Trastornos de la Conducta: conocimiento y acciones de los profesionales de la salud y asistencia social
}

'Universidade de São Paulo. Ribeirão Preto, São Paulo, Brazil.

How to cite this article:

Krauser C, Scherer ZAP, Bueno GAS. Behavior Disorders: knowledge and actions of health professionals and social work. Rev Bras Enferm. 2020;73(1):e20180071. doi: http://dx.doi.org/10.1590/0034-7167-2018-0071

Corresponding Author: Caroline Krauser E-mail: caroline_krauser@hotmail.com

EDITOR IN CHIEF: Dulce Aparecida Barbosa ASSOCIATE EDITOR: Cristina Parada

Submission: 02-15-2018 Approval: 06-08-2018

\begin{abstract}
Objective: to identify the knowledge of professionals of mental health services and social work on Behavior Disorders (BD) in childhood and adolescence, and to analyze their actions in care for children and adolescents with such disorders. Method: a qualitative, descriptive-exploratory study with 13 professionals from two mental health services and two tutorial councils. The data were collected in interviews and submitted to thematic content analysis. Results: three categories emerged from the interviews: "Knowledge about behavior disorders", which defines BD as deviations from normality and lack of limits. "Integrated and group care", which explains the integrated, multidisciplinary and group actions. "Specialized and legal care", which explains the actions through specialized, medical and judicial care. Final considerations: the results point out weaknesses and knowledge gaps of professionals, causing potential harm in the programming of effective actions, such as identification, referral and therapeutic planning.

Descriptors: Behavior Disorder; Conduct Disorder; Child Psychiatry; Health Personnel; Social Work.
\end{abstract}

\section{RESUMO}

Objetivo: identificar o conhecimento dos profissionais de serviços de saúde mental e assistência social sobre os Transtornos de Comportamento (TC) na infância e adolescência, e analisar suas ações na atenção a crianças e adolescentes com tais transtornos. Método: estudo qualitativo, descritivo-exploratório com 13 profissionais de dois serviços de saúde mental e dois conselhos tutelares. Os dados foram coletados em entrevistas e submetidos à análise de conteúdo temático. Resultados: três categorias emergiram das entrevistas: "Conhecimentos acerca dos transtornos de comportamento", que define os TC como desvios da normalidade e falta de limites. "O cuidado integrado e em grupo", que explica as ações integradas, multidisciplinares e através de grupos. "O cuidado especializado e jurídico", que explica as ações através do cuidado especializado, medicamentoso e judicial. Considerações finais: os resultados apontam fragilidades e lacunas de conhecimento dos profissionais acarretando potenciais prejuízos na programação de ações eficazes, como identificação, encaminhamento e planejamento terapêutico.

Descritores: Transtornos do Comportamento; Transtorno da Conduta; Psiquiatria Infantil; Profissionais de Saúde; Assistência Social.

\section{RESUMEN}

Objetivo: identificar los conocimientos de los profesionales de los servicios de salud mental y asistencia social en Trastornos de la Conducta (TC) en la infancia y la adolescencia, y analizar sus acciones en la atención a niños y adolescentes con tales trastornos. Método: estudio cualitativo, descriptivo-exploratorio con 13 profesionales de dos servicios de salud mental y dos consejos de tutoría. Los datos fueron recolectados en entrevistas y sometidos a análisis de contenido temático. Resultados: de las entrevistas surgieron tres categorías: "Conocimiento sobre trastornos de conducta", que define la TC como desviaciones de la normalidad y la falta de límites. "Atención integrada y grupal", que explica las acciones integradas, multidisciplinares y grupales. "Atención especializada y jurídica", que explica las acciones a través de la atención especializada, médica y judicial. Consideraciones finales: los resultados señalan las debilidades y las brechas de conocimiento de los profesionales, causando un daño potencial en la programación de acciones efectivas, como la identificación, la referencia y la planificación terapéutica.

Descriptores: Transtornos de la Conducta Infantil; Transtorno de la Conducta; Psiquiatría Infantil; Personal de Salud; Servicio Social. 


\section{INTRODUCTION}

Behavioral Disorders (BD) in childhood are characterized by two main subtypes: Oppositional Defiant Disorder (ODD) and BD. ODD is characterized by a repetitive and persistent pattern of challenging behavior, such as tantrums and confrontation with authority figures. In Conduct Disorder, the symptoms described in ODD are present, but there is added to them persistent and frequent violation of other people's fundamental rights and social norms such as severe physical assault, theft and property damage $\mathrm{e}^{(1)}$.

In this way, BP diagnostic characteristics are closely related to violence. However, violence and $\mathrm{BP}$ relationship is even more complex and multidirectional. While on the one hand, environmental stressors in periods of greater vulnerability, such as maltreatment and growing in violent communities and schools, significantly increase chances of developing $\mathrm{BP}^{(2-4)}$, on the other hand, once BP is started, there is a greater chance of developing mood, anxiety, and chemical dependency disorders, as well as dropping out of school before high school, engaging in violence and crime, and failing to enter the market work in adult life ${ }^{(5-9)}$.

For these reasons, some countries, such as England and the United States, have adopted theoretical foundations and developed specific protocols to prevent and treat children and adolescents with behavior problems such as Antisocial behaviour and conduct disorders in children and young people: recognition and management ${ }^{(10)}$ (England) and Conduct Problems Prevention Research Group (United States). Through the Fast Track Intervention program, there was an improvement rate of $50 \%$ to $75 \%$ of the severe symptoms of children with Conduct Disorders ${ }^{(11)}$.

In Brazil, as a reference for mental disorders in childhood and adolescence treatment, there are some recommendations, such as those contained in the Caderno de Atenção Psicossocial a Crianças e Adolescentes no Sistema Único de Saúde (SUS - freely translated as Book of Psychosocial Care for Children and Adolescents in the Unified Health System) ${ }^{(12)}$. It is recommended that care for children and adolescents with severe and persistent mental disorders be carried out by the Child Psychosocial Care Center (CAPS- i- Centro de Atenção Psicossocial infantil) with services that make up the network for guaranteeing the rights of children and adolescents such as social welfare services, guardianship councils, prosecution of children and adolescents, among others ${ }^{(12)}$. It is important that this service be integrated, interdisciplinary and through groups with diverse objectives ${ }^{(12)}$.

Furthermore, in relation to situations of violence involving children and adolescents, international organizations, such as the World Health Organization (WHO), bring important theoretical frameworks on prevention actions involving health services and social work. Such referrals aim to reduce violent behavior among children and young people, such as parental education groups, child abuse prevention programs; social skills training; mentoring, and after-school activity programs ${ }^{(13)}$. The WHO also highlights the need for violence prevention programs to be evidence-based and measured against their effectiveness ${ }^{(13)}$.

Despite guidelines and recommendations, there is a significant relationship between BP in childhood and higher rates of serious crimes in Brazil such as homicide and robbery in early adulthood $^{(7-8)}$. Therefore, efforts and investments of different sectors of society are urgent to change this setting: structured prevention plans and treatment and intervention programs based on WHO framework and Book of Psychosocial Care for Children and Adolescents in the Unified Health System not only would they contribute to a better quality of life for the affected individuals as well as potentially, would reduce the rates of violence and crime with inestimable social gains $s^{(2,7,11,13)}$.

However, up to now, there are no Brazilian studies that quantitatively or qualitatively assess interventions related to children and adolescents with BP by the services responsible.

\section{OBJECTIVE}

This study aims to identify the knowledge of professionals of mental health services and social work on BD in childhood and adolescence, and to analyze their actions in care for children and adolescents with such disorders.

\section{METHOD}

\section{Ethical aspects}

The study respected the ethical precepts of human research and was approved by the Research Ethics Committee of Escola de Enfermagem de Ribeirão Preto (EERP-USP). Subjects were informed about anonymity and about the freedom to accept or refuse participation in the research. All persons who agreed to participate in the study signed the Free and Informed Consent Form. For anonymity preservation of participants, the acronyms SW were used to identify professionals that integrate social work councils of the municipality, like tutor advisers and social workers, and $\mathrm{H}$ for health professionals, followed by the number referring to participant order.

\section{Theoretical framework}

Care actions for children and adolescents with BP developed by study participants were analyzed according to references described in the WHO's Book of Psychosocial Care for Children and Adolescents in the Unified Health System ${ }^{(12-13)}$.

\section{Type of study}

This is a qualitative descriptive-exploratory study.

\section{Methodological procedures}

Interviews were collected by the lead author of the study during completion of her academic master's degree. Their insertion in services occurred during multidisciplinary residency course in psychiatry and mental health, where they remained for a period of three to six months in each collection setting. Hence, the residency course allowed the researcher to link with the research subjects and experience in relation to the work processes at each location. Two tools were used to collect the data: a questionnaire with objective questions that addressed demographic data of participants and a semi-structured interview built by researchers, containing 10 questions related to research focus that were recorded in digital audio after their consent. 


\section{Study setting}

The study was carried out with all professionals of four services responsible for serving children and adolescents of a city in the countryside of São Paulo, being a CAPS-i, a Psychiatric Hospital and two Guardianships Councils.

\section{Data source}

Professionals were selected according to the inclusion criteria: to have employment relationship with some of the services and to perform health care or social work of children and adolescents. From this, 23 professionals were included in the research, of which 10 were counselors, six CAPS-i professionals (one nurse, one psychologist, one physician, one social worker and two speech therapists) and seven hospital professionals (three nurses, one physician, one social worker, one psychologist, and one occupational therapist. Of the 23 professionals, four were on vacation at the time of collection and six guardians were refused to participate in the survey, claiming that they did not feel comfortable having the voice recorded, even after confidentiality explanation. Thus, 13 professionals participated in the study.

\section{Collection and organization of data}

The researcher's approach with participants occurred throughout the mental health multidisciplinary residency period performed in the study settings. Before starting collection, a contact was made with the person responsible for each service, and a date was scheduled for study presentation and doubt clarification with professionals. Interviews were collected between October and December 2016, in a place and date chosen by participants, with only the presence of interviewee and researcher. Interviews lasted from 20 to 50 minutes, recorded in digital audio and transcribed in full for analysis.

\section{Data analysis}

The technique used for the data treatment was Bardin's content analysis ${ }^{(14)}$. In order to do so, text skimming of interviews was carried out, which allowed the identification of similar meaning units that presented contents about BP knowledge and actions of professionals in care for children and adolescents with diagnosis.

\section{RESULTS}

With regard to professional characterization, five were from CAPS-i (a nurse, a psychologist, a speech therapist, a social worker and a physician), four were from Hospital Espírita de Marília (a psychologist, an occupational therapist, a nurse and a physician), and four were from the Guardianship Council (four guardians' councilors). No professional had received training on prevention or care measures for children and adolescents with mental disorders.

The three thematic categories that emerged from the professionals' interviews were: 1) knowledge about BP that is a deviation from normality, lack of education or limit and as part of other psychopathologies of childhood and adolescence; 2) integrated and group care that describes the integrated, multidisciplinary group actions developed by professionals; 3) specialized and legal care that describes the actions of professionals related to specialized, medical and judicial care.

\section{Knowledge about Behave Disorders}

Professionals understand BP as those who "deviate from a standard considered normal". They are changes that are therefore disorienting or out of the usual and expected pattern of the conduits for the age and culture of a child or adolescent:

Behavior disorders in childhood are those that are seen as disoriented, which are not well accepted, neither by parents nor by society. $(\mathrm{H} 3)$

Every behavior disorder is what does not resemble what is common, something that will bother society, bother the family and bring some harm to the child. $(\mathrm{H} 1)$

It is, I believe it is a behave profile that the child has throughout his development that deviates from a pattern taken as normal [...] will be a deviant behavior that has a mood that is also changed from the normal pattern [...]. (H5)

Descriptive and definitive BP characteristics appear punctually, with aggressiveness and challenge attributes:

[...] that aggressive behavior, the person does not want to go to school, anyways [...]. (SW9)

[...] but it's that person who defies anything, she defies the fight, defies the word, she curses, so that would be more or less. (SW11)

Social work professionals compare BPs with lack of education, lack of limits, rebellion or rascality:

[...] there are many behave disorders that really are like rebelliousness. (SW11)

Behavior disorders in childhood are those that end up making the child be seen as impolite, as a child that has no limit, so it overlaps with other children, most often in a negative way, because it is a child who does not know how to behave [...]. (SW9)

[...] they end up causing the child to be seen as impolite, a child who has no limit [...]. (S10)

[...] even if the child has this pathology, it is also seen as rascality [...]. (SW12)

For a health professional, understanding children and adolescents with BP as impolite ends up making it difficult to refer them to mental health services. He mentioned that there should be a professional to detect mental health cases:

[...] the child or adolescent who has this disorder is seen as impolite, and then I think they are referred or look for this service as one of the last or last but one of the alternatives, when they have 
exhausted all the other jobs they end up looking for mental health institutions [...] is that they leave as a last resort, lack of referral, lack of a professional that is detecting whether it is a mental health issue or not, right? $(\mathrm{H} 7)$

They believe that there are several BPs and cite examples such as attention deficit hyperactivity disorder, chemical dependency, learning disorder, mood swings, isolation, suicidal ideation, selfmutilation and disconnection with reality:

So they have been presenting cases of hyperactivity, behavior disorders, such as conduct disorder and other issues as well, that we may be seeing more ahead there [...]. (S2)

A deviant behavior that has a mood that is also changed from the normal pattern, which I think is related to learning difficulty [...]. (H5)

When we talk about behavior disorder, more focused on the case of chemical dependence, so we see, conduct disorders, learning disorder [...]. (H8)

Look, there are several child behavior disorders, such as hyperactivity disorder, attention deficit, opposition disorder or conduct, in. (H6)

[...] / understand that behavior disorder is a disconnection of the child from reality [...]. (SW12)

[...] or it can also be that child who isolates, who does not talk, extremely shy, does not play, who is isolated [...]. (H3)

[...] many times we see here the adolescent with this disorder has a suicidal impulse, self-mutilation and drug use, anyway, where it leads to, right? ( $\mathrm{H} 13)$

One professional in this study used the term sociopathy when referring to a child with BP. When mentioning that patient was manipulating the other minor inpatients, the professional suggests that changes should take place in Brazilian legislation:

We do not have a good specific site for the treatment of conduct disorder and chemical dependence [...] we have a very satisfactory relationship initially with the judiciary, which allowed that there were minors who presented violent antisocial behavior here. [...] for example, there was a situation that I had a minor, was a sociopath of 7 years, and then the judge sent us. He was once restrained on the stretcher, let go, and played with the others he was manipulating [...] then there had to be other measures because they were adolescents. Until 18 you can kill right then you cannot kill more, so it's complicated legislation in Brazil, it would have to have a lot of change [...]. ( $\mathrm{H} 8)$

\section{Integrated and group care}

Some health professionals mentioned that services are provided by several professionals and services that work together to form a protection and support network for children and adolescents. They also stated that the treatment environment is "a place of social inclusion and the restructuring of the family network, the child support network, both the family and school support network, and the health network also".
[...] they all come together, sit down, discuss what would be best for this child, and then one goes home to do a home visit to help that child fit into the family environment. The other goes to school to try to help teachers adapt this curriculum, to do activities that include the child, which mediate their activities with the other children. The other goes to other therapeutic settings, discuss conduct, so I think this is a place of social inclusion and the restructuring of the family network, the child support network, both the family and school support network, and the health network also [...]. (H7)

[...] so the social worker here does a very good job, she goes to the house, sees what's really going on there and tries to do a job inside the house. People who have the opportunity, go to school, always call at school, send report, talk, go and try to make this insertion of the child in the social environment, the safety net is very important [...] we schedule a meeting, they come, we go with the $B H U$, with the health of the family, with the child's health, with these child support networks [...]. ( $\mathrm{H} 13)$

Group care is cited as the main intervention strategy. They mentioned that groups are made according to demand and labor through movies and games. They reported not using specific strategies for the treatment of BD in children and adolescents:

[...] she performs direct work with each family according to demand. What comes of demand we try to supply, but there is no ongoing specific behave disorder work [...]. ( $\mathrm{H} 13)$

[...] we, who stay here always, there are some groups that we work according to the demand, then we see more or less the age of the child, which combines with which by the type of symptom. By the demand, we are joining and doing some groups, we mark a movie, brand group of games at the same time, as the demand is appearing and as we have labor, but nothing specific for behavior disorder [...]. (H6)

I think this part of behavior disorder needs to create a group work that has not yet been carried out, not really [...]. (H7)

\section{Specialized and legal care}

A social care professional mentioned the psychological and medical treatment. She reported that "when the psychologist does not handle it" they require treatment with a neurologist or psychiatrist:

[...] taking to a psychologist, treatment would be the psychologist, when the psychologist does not handle it, when it is well advanced, that is already in the psychologist and exhausted, then we require a neuro treatment and often the psychiatric as well [...]. (SW12)

Health professionals and social workers have mentioned that treatment should be carried out by specialized professionals. They emphasized the use of medication above all, since "without the medication the child has no control":

[...] with a psychologist, with a technical team, right? So this treatment would only be through specialized professionals [...]. (SW9)

[...] because parents often do not accept that the child has a disorder, including medication, above all because without the 
medication, the child has no control, when it is well advanced this disorder. (SW12)

Regarding BP medication and treatment, professionals of this study mentioned the use of mood stabilizers and transcranial electrostimulation:

[...] with transcranial electrostimulation use [...] the use of more advanced drugs, mood stabilizers of more advanced generation [...]. ( $\mathrm{H} 8)$

In cases of misbehavior or school drop-out, social work professionals report applying foreseen judicial measures in case of violation of the rights of children and adolescents, such as warnings, and forum referral and prosecution. When there is negligence on the part of parents, professionals also use warning application and forum referral. In this case, the judge is the one who determines measures that will be taken, which can take in a prison of 15 days to 3 months:

[...] usually a rebellious adolescent who does not like to go to school, that is, ends up giving that drop-out, and on top of the article, we have to apply the measure of article 101 [...] we have to apply a warning in him, and in the case of three warnings, we send him to the forum, to be responding to this situation of school dropout. (SW12)

Now if it's a warning, a child who did the wrong thing at school, they come here together with the family, give a warning, or if the country is not fulfilling the role within the ECA law, then we give a warning and forwards, if applicable, to the prosecution [...]. (SW10)

If it ever happens that we have a situation of neglect of the mother, for example, the mother drinks, we refer to the forum. The judge who will determine, the law says he can even a prison from 15 days to 3 months because he has had a violation of the law. So we'll take care of the situation here and then forward to the forum. (SW11)

\section{DISCUSSION}

This study identified important weaknesses and knowledge gaps among professionals in relation to BP. Inadequately, for them disorders are not characterized only by ODD and Conduct Disorder, but as a deviation from any behavioral pattern considered normal for the child's and adolescent's age and culture, as well as rebellion, lack of education and lack of limits. However, all psychopathologies are characterized by changes in the behavior and/or personality of the individual, which result in damages to their personal, social and occupational development, these characteristics being not exclusive to $\mathrm{BP}^{(1)}$.

This result makes it possible to infer that some professionals may not understand BP as a specific diagnosis, but as a symptom or a behavioral change that may be present, regardless of the diagnosis of ODD or Conduct Disorder. This inference is evidenced when other psychopathologies such as attention deficit hyperactivity disorder, chemical dependence, learning disorder and other behaviors such as isolation, suicidal ideation, self-mutilation and disconnection with reality are also categorized as BP.

Confusion between maladaptive behaviors and the nosological entity BD can lead to impairments in specificity and effectiveness not only in identification but also in treatment, since there are great differences in the therapeutic planning indicated for the different disorders misunderstood as $\mathrm{BP}^{(15)}$.

One of the study's professionals still refers to children and adolescents with BP as carriers of sociopathy, a term used to refer to antisocial personality disorder. This association may have occurred because of some characteristics common to both disorders, such as frequent violation of other people's rights ${ }^{(1)}$. However, the relationship between presenting BP in childhood or adolescence and developing antisocial personality disorder in adulthood is not definitive. There is considerable heterogeneity in relation to $\mathrm{BP}$ evolution, and children and adolescents with similar signs and symptoms often have different outcomes over time ${ }^{(16)}$. In addition, antisocial personality disorder should only be diagnosed after the age of $18^{(1)}$.

Similar to what was found in this study, a review on the subject points out that when the diagnosis of BP is unknown. The use of colloquial terms such as sociopathy or psychopathy to refer to young people with $\mathrm{BD}$ is common, however it entails a more pessimistic view of health professionals and of justice regarding adolescent rehabilitation, reducing the chances of being referred to a treatment service and favoring punitive measures ${ }^{(17)}$. This conception could be observed in this study, when the professional interviewed, when referring to an adolescent with BP as a sociopath, ends up reinforcing the need for changes in Brazilian legislation for adolescents who commit infractions at the expense of psychosocial approaches.

BP signs and symptoms as described in diagnostic manuals, such as aggressiveness and noncompliance with rules were mentioned by only two professionals. However, when mentioning aggressiveness, professionals did not delineate in what context this behavior may indicate a problem that needs treatment. Understanding any aggressive and challenging behavior as a $\mathrm{BP}$, as put in the speeches of these professionals, can make children and adolescents adapted to violent environments, such as street children or communities with high rates of violence, be reduced to children with disabilities. psychopathology ${ }^{(18)}$.

On the other hand, understanding problems of behavior such as rebelliousness or a mere educational failure of parents and relatives can result in a simplification of problematic and consequent therapeutic plan that is impoverished and insufficient for real demands ${ }^{(19)}$. This fact is evidenced in the speech of a professional of this study who identifies that the conception that children and adolescents with BP are rebellious or impolite makes it difficult to refer them to mental health services, since in understanding of $\mathrm{BP}$, professionals do not associate them to a health problem, but to a characteristic of the child or adolescent's personality.

From these conceptions, it can be inferred that there are weaknesses and knowledge gaps of professionals about BP, which may justify, in part, the difficulty in identifying and effective therapeutic and evidence-based planning for children and adolescents with the diagnosis. For example, the value attributed to medication, medical and specialized work, and exclusively judicial practices to give resolution to disorder behavior characteristic.

For some practitioners, medication is enhanced as BP primary therapy. Contrary to this result, psychosocial approaches are those with greater evidence for diagnosis clinical improvement. The Book 
of Psychosocial Care for Children and Adolescents in the Unified Health System also emphasizes that care for children and adolescents with mental disorders should not be focused on medication ${ }^{(12)}$.

The physician's figure is not evidenced by professionals as part of the health care team of the child or adolescent, but in a hierarchical way, being mentioned as superior to that of the psychologist, since the psychiatrist "handles" what is more advanced and serious and that the psychologist failed to give resolution, reinforcing the biomedical model.

Another treatment modality evidenced as necessary for BP was transcranial electrostimulation, mentioned by one of the professionals of this study. However, the use of this procedure has robust evidence of improvement in the treatment of depressive disorders, and its use in other psychiatric disorders lacks evidence ${ }^{(20)}$.

Just as health practices based on the biomedical model are identified, it is also possible to observe social work practices similar to those foreseen by the old code of minors, which aimed at corrective and repressive measures. In understanding adolescents with $\mathrm{BP}$ as a rebel, it is possible to perceive that professionals actions are focused strictly on the punitive measures foreseen in the Child and Adolescent Statute (ECA - Estatuto da Criança e do Adolescente), like warning, fine and even prison ${ }^{(21)}$, This corroborates the hypothesis that the professionals' knowledge gaps in relation to BP make it difficult to identify and elaborate an effective treatment.

In this sense, although the medical diagnosis is not an assignment of other professionals, it would be important for them to have a minimum training that would allow them to identify BP behaviors characteristic in order to refer them to the appropriate services. The guardianship council is considered the gateway for children and their families in the child protection network ${ }^{(22)}$, and receives a large proportion of children and adolescents who present behavior problems. In an analysis carried out in the city of Ribeirão Preto, school dropouts and behavior problems occupied the fourth and fifth place of referrals to the tutelary board ${ }^{(23)}$, emphasizing the importance of these professionals in the early BP identification.

In some countries, government agencies responsible for developing health policies have developed specific manuals for identifying and treating BP such as the Conduct Problems Prevention Research Group ${ }^{(2,11)}$ (USA) and Antisocial behaviour and conduct disorders in children and young people: recognition and management of National Institute Of Health And Care Excellence $(\mathrm{NICE})^{(10)}$ (England). In this last one, there is a description of BP problems in the country and regulations for actions of selective prevention and care of the disorders involving different organs of care, mainly health professionals and social work. The material presents the most appropriate scales to identify subclinical signs and new BP cases, and then provides recommendations on how to proceed for each score identified on the scale $\mathrm{e}^{(10)}$.

Thus, even professionals who do not have mastery over the diagnostic criteria can identify cases of risk for developing BP during childhood, performing appropriate referrals or treatments. WHO also recommends the existence of mechanisms to coordinate activities among different sectors of care for children and adolescents in situations of violence, in order to ensure effective collaboration between them ${ }^{(13)}$.

Collaboration between the different services is in the main potentiality pointed out by professionals, which emphasize interdisciplinary and multidisciplinary actions. The interventions mentioned denote articulation between the different environments in which children and adolescents live together, such as school, family and leisure spaces, in order to provide an integrated and interdisciplinary health treatment.

This result is in agreement with studies that assessed therapeutic modalities for BP clinical improvement, which point out the union between the individual care of the child and the adolescent, their relatives and of interventions in the schools as more effective when compared to these isolated interventions ${ }^{(24)}$. The Book of Psychosocial Care for Children and Adolescents in the Unified Health System and WHO Report also recommend integrated, interdisciplinary care and preferably through groups with diverse objectives ${ }^{(12-13)}$.

Group interventions are another modality of treatment evidenced by professionals. However, the lack of evidence-based therapeutic approaches to improve BP or disruptive behaviors. According to professionals' reports, the groups are elaborated according to the age group of patients, the demand for care and the availability of professionals in the service. The main modalities cited were film and gaming groups.

It is emphasized that no interviewee mentioned groups using structured intervention techniques and based on clinical evidence for antisocial behavior improvement, such as parental training groups, social skills training group, or cognitive-behavioral therapy group $^{(2,10-11,25)}$, which are also part of WHO recommendations ${ }^{(13)}$.

In the opposite direction, studies and projects that obtained the best results in reducing signs and symptoms of BP performed groups with specific technical interventions based on evidence. One of the examples is the Fast Track Project, formed by the United States Behavior Prevention Group, which encompasses activities such as: social skills and emotional regulation groups and parental training groups ${ }^{(2,11)}$, reaching an index of $75 \%$ improvement in children and adolescents with severe symptoms of Conduct Disorder ${ }^{(11)}$.

In Brazil, no records were found in the literature, demonstrating BP improvement indexes in children and adolescents seen in CAPS-i, which is, in turn, the reference site for the treatment of mental disorders in childhood. This corroborates what was pointed out in WHO report, which notes that most action plans to prevent violent behavior in middle-income countries are not subsidized by data ${ }^{(13)}$.

Thus, it can be seen that in relation to BP, the interventions performed by professionals are integrated and interdisciplinary, which according to clinical studies assessing effective interventions for BP, present an important potential for symptom improvement. However, the approaches used jointly by these professionals are not based on therapies that are more supported by clinical evidence for BP treatment ${ }^{(2,11,25)}$ or $\mathrm{WHO}$ recommendations ${ }^{(13)}$.

One of the possible explanations for this result is that there are no manuals, protocols or programs that describe how care should be performed in cases of specific psychopathologies such as BP. The educational and manual materials that guide the mental health work in Brazil focus on detailing integrated and interdisciplinary actions, such as Single Therapeutic Project (PTS - Projeto Terapêutico Singular) elaboration ${ }^{(12)}$.

This focus on integrated and multidisciplinary care and the lack of protocols on how to proceed in relation to the different 
mental disorders in childhood and adolescence by the manuals of health care and social care services can explain why, although care is integrated, there is a lack of evidence-based interventions for BP treatment in childhood.

The fact that professionals do not receive training to serve children and adolescents with mental disorders, as observed in the characterization form of the participants of this research. This result is in line with that recommended by the WHO, which emphasizes as fundamental the professional training for the development of actions to prevent and treat situations of violence ${ }^{(13)}$.

Thus, in order for the integrated and interdisciplinary care provided by professionals to be effective, it is necessary for professionals to receive adequate training regarding diagnostic and treatment characteristics for BP, which could be done through matrix and continuous and permanent education between services health and social work. The use of objective scales and criteria and the construction of protocols and structured flowcharts can also contribute to a better work qualification and effectiveness.

\section{Study limitations}

One of the study limitations was participation refusal of CREAS professionals in the city, as it is an important service in care for children and adolescents with BP. Reduction of the number of professionals, especially of tutorial counselors, may confer gaps in relation to the knowledge and actions of this professional category. Due to the dissertation deadline that originated this work and the distance between the city where authors reside and in which collection was performed, it was not possible to present the results to participants before the end of the work.

\section{Study contributions}

The study is a pioneer in investigating conceptions and practices carried out by health professionals and guardianship advice regarding children and adolescents with BP. The results highlight the importance of enabling professionals to identify and offer appropriate treatment to young people who have disruptive behaviors, considering BP contribution in the development of other psychopathologies and criminality ${ }^{(5-8)}$.

For better care, it is recommended that professionals be trained in the signs and symptoms of BP in order to identify cases of risk or in need of psychosocial treatment. Another recommendation concerns the construction of clear and evidence-based flowcharts between all services that serve children and adolescents in relation to actions that should be taken if significant risk factors or signs and symptoms of BP.

Finally, professionals in specialized services should be trained to carry out preventive actions for BPs, such as parental education, mentoring programs and the development of social skills.

\section{FINAL CONSIDERATIONS}

The results indicate weaknesses and knowledge gaps of professionals in relation to the main characteristics of $\mathrm{BP}$, which are understood as deviations from normality and as lack of education or limits. Such conceptions raise difficulties in the identification, referral and treatment of children and adolescents diagnosed with the disorder.

As a potential, professionals refer to interdisciplinary and integrated actions implementation, which meet the recommendations of WHO's Book of Psychosocial Care for Children and Adolescents in the Unified Health System. However, such actions lack evidence-based strategies for BP clinical improvement or for reduction of disruptive behaviors in children and adolescents, such as the parental training group and social skills.

\section{FUNDING}

Coordenação de Aperfeiçoamento de Pessoal de Nível Superior (CAPES).

\section{REFERENCES}

1. American Psychiatric Association. Manual diagnóstico e estatístico de transtornos mentais: DSM-5. $5^{\mathrm{a}}$ ed. Porto Alegre: Artmed; 2014.

2. Pasalich DS, Witkiewitz K, McMahon RJ, Pinderhughes EE. Indirect effects of the fast track intervention on conduct disorder symptoms and callous-unemotional traits: distinct pathways involving discipline and warmth. J Abnorm Child Psychol. 2016;44(3):587-97. doi: 10.1007/ s10802-015-0059-y

3. Shaw DS, Sitnick SL, Reuben J, Dishion TJ, Wilson MN. Transactional effects among maternal depression, neighborhood deprivation, and child conduct problems from early childhood through adolescence: a tale of two low-income samples. Dev Psychopathol. 2016;28(3):81936. doi: $10.1017 /$ S095457941600033X

4. Kyranides MN, Fanti KA, Katsimicha E, Georgiou G. Preventing conduct disorder and callous unemotional traits: preliminary results of a school based pilot training program. J Abnorm Child Psychol. 2018;46(2):291-303. doi: 10.1007/s10802-017-0273-X

5. Aebi M, Barra S, Bessler C, Steinhausen HC, Walitza S, Plattner B. Oppositional defiant disorder dimensions and subtypes among detained male adolescent offenders. J Child Psychol Psychiatry. 2016;57(6):729-36. doi: 10.1111/jcpp.12473

6. Erskine HE, Norman RE, Ferrari AJ, Chan GC, Copeland WE, Whiteford HA, et al. Long-term outcomes of attention-deficit/hyperactivity disorder and conduct disorder: a systematic review and meta-analysis. J Am Acad Child Adolesc Psychiatry. 2016;55(10):841-50. doi: 10.1016/j.jaac.2016.06.016

7. Murray J, Cerqueira DRC, Kahn T. Crime and violence in Brazil: systematic review of time trends, prevalence rates and risk factors. Aggress Violent Behav. 2013;18(5):471-83. doi: 10.1016/j.avb.2013.07.003

8. Murray J, Menezes AM, Hickman M, Maughan B, Gallo EA, Matijasevich A et al. Childhood behaviour problems predict crime and violence in late 
adolescence: Brazilian and British birth cohort studies. Soc Psychiatry Psychiatr Epidemiol. 2015;50(4):579-89. doi: 10.1007/s00127-014-0976-z

9. Frick PJ. Early identification and treatment of antisocial behavior. Pediatr Clin North Am. 2016;63(5):861-71. doi: 10.1016/j.pcl.2016.06.008

10. National Institute of Health and Care Excellence (NICE). Antisocial behaviour and conduct disorders in children and young people: recognition, intervention and management [Internet]. London: NICE; 2013 [cited 2017 Nov 23]. Available from: https://www.sbp.com.br/fileadmin/user_ upload/pdfs/Antisocial_behaviour_conduct_children_young_people-recognition_intervention_management-NHS2013.pdf

11. Dodge KA, McCourt SN. Translating models of antissocial behavioural development into efficacious intervention policy to prevent adolescent violence. Dev Psychobiol. 2010;52(3):277-85. doi: 10.1002/dev.20440

12. Ministério da Saúde (BR). Atenção psicossocial a crianças e adolescentes no SUS: tecendo redes para garantir direitos [Internet]. Brasília: Ministério da Saúde; 2014 [cited 2017 Nov 25]. Available from: http://bvsms.saude.gov.br/bvs/publicacoes/atencao_psicossocial_criancas_ adolescentes_sus.pdf

13. World Health Organization (WHO). Global status report on violence prevention [Internet]. Geneva: WHO; 2014 [cited 2017 Nov 20]. Available from: http://apps.who.int/iris/handle/10665/145086

14. Bardin L. Análise de conteúdo. 3a ed. Lisboa: Edições 70; 2004.

15. Masi G, Manfredi A, Nieri G, Muratori P, Pfanner C, Miloni A. A naturalistic comparison of methylphenidate and risperidone monotherapy in drug-naive youth with attention-deficit/hyperactivity disorder comorbid with oppositional defiant disorder and aggression. J Clin Psychopharmacol. 2017;37(5):590-4. doi: 10.1097/JCP.0000000000000747

16. Petersen IT, Bates JE, Dodge KA, Lansford JE, Pettit GS. Describing and predicting developmental profiles of externalizing problems from childhood to adulthood. Dev Psychopathol. 2015;27(3):791-818. doi: 10.1017/S0954579414000789

17. Frick PJ, Ray JV, Thornton LC, Kahn RE. Can callous-unemotional traits enhance the understanding, diagnosis, and treatment of serious conduct problems in children and adolescents? A comprehensive review. Psychol Bull. 2014;140(1):1-57. doi: 10.1037/a0033076

18. Scivoletto S, Stivanin L, Ribeiro ST, Oliveira CCC. Avaliação diagnóstica de crianças e adolescentes em situação de vulnerabilidade e risco social: transtorno de conduta, transtornos de comunicação ou "transtornos do ambiente"? Rev Psiquiatr Clín. 2009;36(5):206-7. doi: 10.1590/ S0101-60832009000500006

19. Stefanini JR, Scherer ZAP, Scherer EA, Cavalin LA, Guazzeli MS. Adolescents with attention deficit hyperactivity disorder and exposure to violence: parents' opinion. Rev Latino-Am Enfermagem. 2015;46(6):1090-6. doi: 10.1590/0104-1169.0249.2653

20. Philip NS, Nelson BG, Frohlich F, Lim KQ, Widge AS, Carpenter LL. Low-intensity transcranial current stimulation in pshychiatry. Am J Psychiatry. 2017;174(7):628-39. doi: 10.1176/appi.ajp.2017.16090996

21. Câmara dos Deputados (BR). Estatuto da Criança e do Adolescente: lei n 8.069, de 13 de julho de 1990, e legislação correlata. $11^{a}$ ed. Brasília: Edições Câmara; 2014.

22. Girade HA, Didonet V, coordenadores. O município e a criança de até 6 anos: direitos cumpridos, respeitados e protegidos. Brasília: Fundo das Nações Unidas para a Infância (UNICEF); 2005.

23. Bazon MR. Violências contra crianças e adolescentes: análise de quatro anos de notificações feitas ao Conselho Tutelar na cidade de Ribeirão Preto, São Paulo, Brasil. Cad Saúde Pública. 2008;24(2):323-32. doi: 10.1590/S0102-311X2008000200011

24. Comer JS, Chow C, Chan PT, Cooper-Vince C, Wilson LAS. Psychosocial treatment efficacy for disruptive behavior problems in very young children: a meta-analytic examination. J Am Acad Child Adolesc Psychiatry. 2013;52(1):26-36. doi: 10.1016/j.jaac.2012.10.001

25. Epstein R, Fonnesbeck C, Williamson E, Kuhn T, Lindegren ML, Rizzone K, et al. Psychosocial and pharmacologic interventions for disruptive behavior in children and adolescents [Internet]. Rockville: Agency for Healthcare Research and Quality (AHRQ); 2015 [cited 2017 Nov 20]. Available from: https://effectivehealthcare.ahrq.gov/sites/default/files/pdf/disruptive-behavior-disorder_research.pdf 